\title{
Acute Respiratory Failure in a Patient With Idiopathic Pulmonary Fibrosis Following Nebulized and Intravenous Stem Cell Therapy
}

\author{
Kelly L. Cervellione ${ }^{\mathrm{a}, \mathrm{d}}$, Janaya Raynor ${ }^{\mathrm{a}}$, Parool Desai ${ }^{\mathrm{b}}$, Craig A. Thurm ${ }^{\mathrm{c}}$
}

\begin{abstract}
Idiopathic pulmonary fibrosis (IPF) is an uncommon disease with a poor prognosis. Recently, two medications were approved to slow progression of disease. However, due to the limited treatment options available, patients and their families often look to experimental and off-label treatments for support. One such option is stem cell therapy, which can be delivered in a variety of ways. Stem cells are being utilized both in and out of the context of closely monitored clinical trials. However, there is little evidence regarding the safety and efficacy of stem cell therapy for patients with IPF. Here we describe a case of a patient who received intravenous and nebulized stem cell therapy, which was followed by an acute exacerbation of his IPF. The exacerbation was successfully treated with corticosteroids and supportive care.
\end{abstract}

Keywords: Idiopathic pulmonary fibrosis; Stem cell therapy; Exacerbation

\section{Introduction}

Idiopathic pulmonary fibrosis (IPF) is an uncommon, devastating disease with a prognosis of 3.5 - 5 years from the time of initial diagnosis $[1,2]$. Given the limited treatment options and poor prognosis of IPF, patients and their families are drawn to experimental treatments to help prolong life and improve symptoms. One such treatment that has received much recent publicity is stem cell therapy. However, there are limited data on its safety and efficacy in IPF. Patients have been receiving

\footnotetext{
Manuscript submitted June 26, 2017, accepted July 25, 2017

aDepartment of Clinical Research, Jamaica Hospital Medical Center, Jamaica, NY, USA

bParool Desai Consultations, Jupiter, FL, USA

${ }^{\mathrm{c}}$ Department of Pulmonary Medicine, Jamaica Hospital Medical Center, Jamaica, NY, USA

${ }^{\mathrm{d} C}$ Corresponding Author: Kelly Cervellione, Jamaica Hospital Medical Center, 8900 Van Wyck Expressway, Jamaica, NY 11418, USA.

Email: kcervell@jhmc.org
}

doi: https://doi.org/10.14740/jmc2876e stem cell therapy by various techniques both in the context of carefully supervised clinical trials as well as more loosely monitored settings.

We present a case of a patient with IPF who developed acute respiratory failure after undergoing intravenous (IV) and nebulized stem cell replacement therapy. High-resolution CT scan showed extensive ground glass attenuation in a "crazy paving" pattern in a perihilar distribution superimposed on his chronic pulmonary fibrosis [3]. Stem cell replacement was felt to be the most likely trigger of his exacerbation. He responded rapidly to corticosteroid therapy.

\section{Case Report}

A 72-year-old male diagnosed with IPF 4.5 years prior to presentation and maintained on home oxygen presented with progressively worsening shortness of breath and cough over 1 week. He denied fever, chills, sputum production and chest pain. He had no prior IPF exacerbations. The patient reported that he had received IV and nebulized stem cell therapy through an experimental program 4 weeks prior to and again 2 weeks prior to the current admission. The procedures were completed as part of a patient-funded experimental program where stem cells were harvested from adipose tissue, cultured, and reintroduced to the patient intravenously and via nebulizer.

Of note, upon admission to the hospital, a copy of the study consent form was requested in order to better understand the procedures the patient underwent as part of the program. Unfortunately, the consent form was very limited and did not explain the reason the patient received the stem cell treatment, the methods employed for harvesting and re-introducing the stem cells, and the known or potential side effects from the treatment. Conversation with the doctor who administered the therapy confirmed that the patient received adipose-derived autologous stem cells via IV and nebulization. He reported that there were no potential side effects to the procedure, which was consistent with what the patient had been told.

Other medical problems included diabetes, hypothyroidism, gastroesophageal reflux and anemia. On EMS arrival, he was tachypneic and tachycardic with an oxygen saturation of $68 \%$ on $2 \mathrm{~L}$ nasal cannula; $100 \%$ non-rebreather facemask improved saturation to $85 \%$. He was normotensive. He was afebrile but developed a transient fever shortly after admission. 

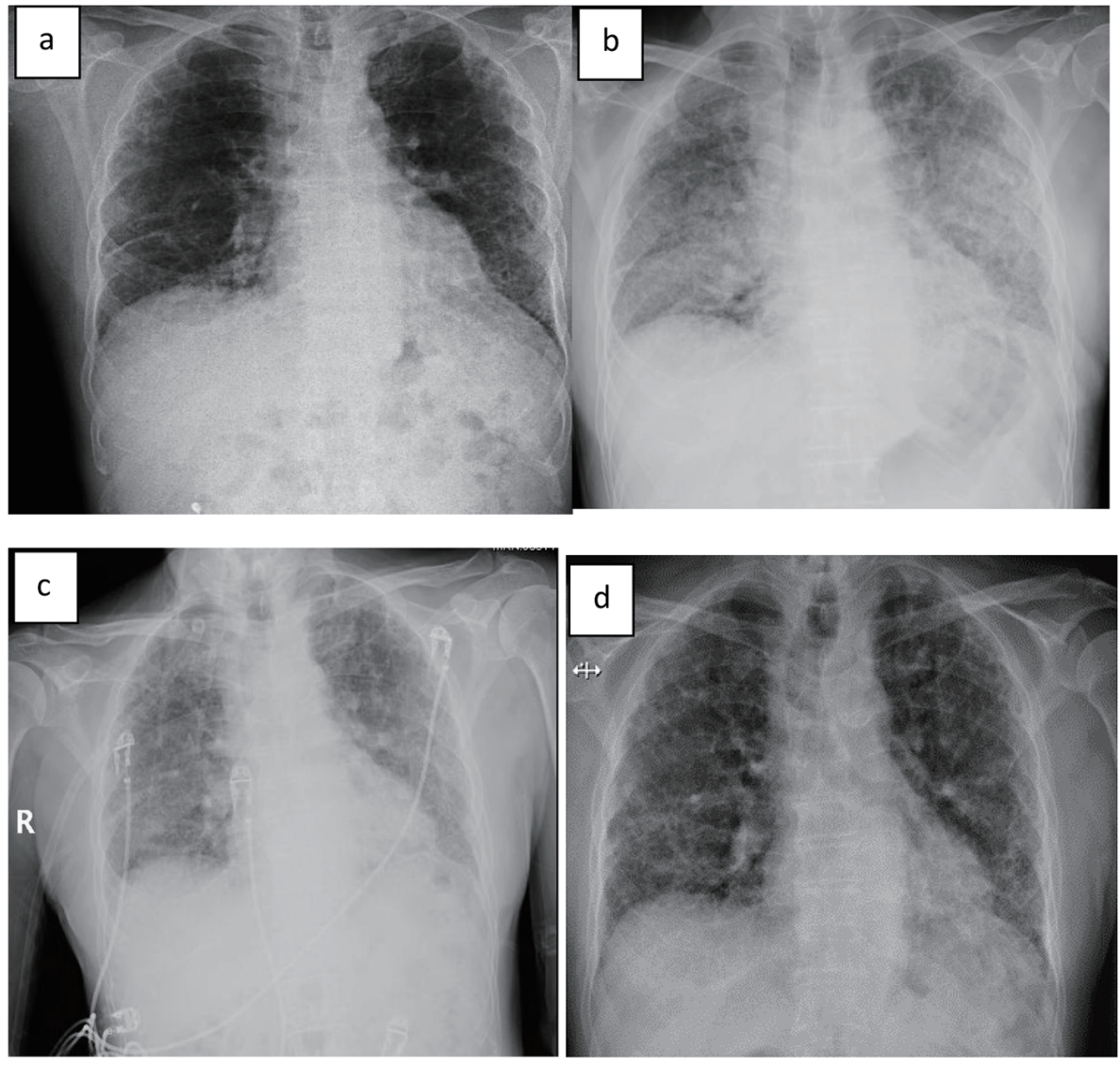

Figure 1. (a) X-ray 12 months prior to admission, (b) on day of admission, (c) on day 2 of admission, and (d) 10 days after discharge.

On exam, he appeared malnourished and fatigued. Lungs had bilateral lower lobe rales, without wheeze or evidence of consolidation. Labs were significant for elevated WBC (17.6), glucose (299), BUN (32), creatinine (1.2), anion gap (21), and

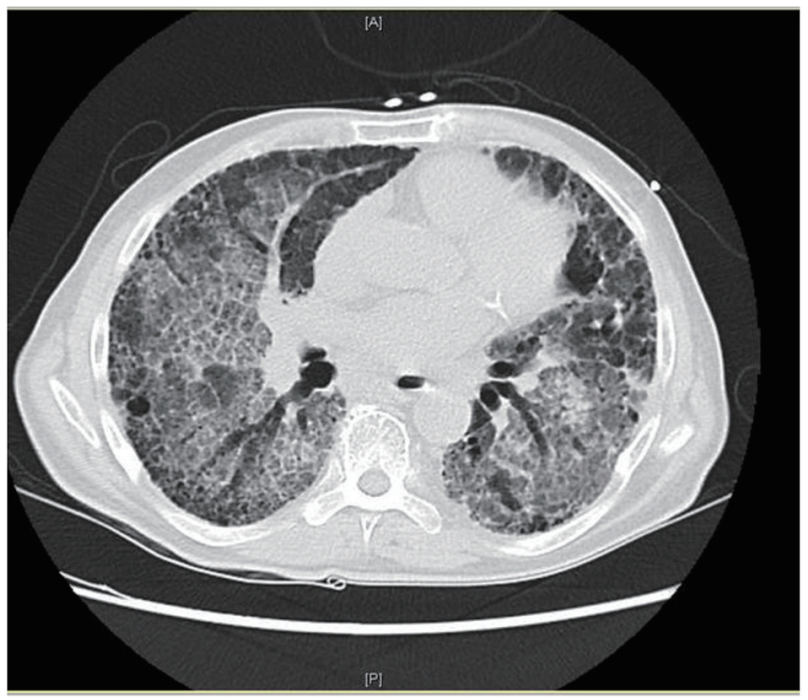

Figure 2. High-resolution CT scan from admission. lactic acid (6.5). Mild anemia was also noted. Rapid influenza, urine legionella antigen, and urine streptococcal pneumonia antigen were negative. Chest radiograph revealed diffuse infiltrates in both lungs, much increased from last study 12 months earlier (Fig. 1a, b). The patient was started on methylprednisolone $40 \mathrm{mg} \mathrm{q} 8 \mathrm{~h}$, vancomycin, piperacillin/tazobactam and levaquin. High-resolution CT scan showed extensive ground glass attenuation in a "crazy paving" pattern in a perihilar distribution superimposed on extensive interstitial lung disease (Fig. 2). The apices were spared.

Lactate rapidly improved and normalized within $5 \mathrm{~h}$. He was maintained on BIPAP and demonstrated significant improvement in oxygenation within $12 \mathrm{~h}$. By day 2, the patient reported feeling less dyspneic and his chest X-ray demonstrated improvement in the bilateral infiltrates (Fig. 1c). By day 3 , these were markedly improved. He remained on BIPAP for 3 days. Cultures were unrevealing and antibiotics were narrowed; he completed a course of levaquin. IV corticosteroids were continued for 5 days at which time oral prednisone was started. By day 5, oxygen saturation had improved to $96 \%$ on $2 \mathrm{~L}$ via nasal cannula at rest.

The patient was discharged on $40 \mathrm{mg}$ prednisone and supplemental oxygen at $2 \mathrm{~L} \mathrm{NC}$. Prednisone was tapered down over several weeks with close follow-up. Chest X-ray 10 days after discharge revealed complete resolution of the alveolar in- 
filtrates (Fig. 1d).

\section{Discussion}

Complete reviews regarding the potential of stem cells for treating pulmonary disease can be found elsewhere [4-6]. Briefly, when appropriately selected, screened, and implanted, stem cells may have the ability to repair and regenerate damaged tissues in the body. One theory of IPF pathogenesis is that epithelial injury, abnormal re-epithelialization, deposition of fibroblasts and microfibroblasts, and scarring of the lung parenchyma contribute to the disease. Hypothetically, stem cell treatment could contribute to cell repair and regeneration [5, 7]. Thus far, human studies in patients with lung disease are few in number with small sample sizes.

In published and ongoing studies in patients with IPF, several techniques of harvesting stem cells have been utilized. Sources have included bone marrow [8-10], adipose tissue [11], lung (from both live and deceased donors) [12], and placentas [13]. Once cultivated, several ways of reintroducing stem cells have been described, including by IV infusion $[8$, $10,14]$, nebulization and bronchoscopy $[11,12]$. In our patient, adipose tissue was used for stem cell harvesting and reintroduction was performed intravenously and via nebulizer.

Given the limited therapies for IPF, patients are drawn to experimental medications and off-label treatments, such as stem cell therapy. There has been a paucity of studies published in this area and few trials registered in clinicaltrials.gov. In the small number of IPF patients whom have been reported on, there have been no serious adverse events identified. One patient in the Serrano-Mollar study developed a transitory alveolar infiltrate and hypoxemia after cell instillation that responded rapidly to steroids [12]. Chambers and colleagues reported only mild adverse events, including a transient decrease in arterial oxygen saturation [13]. Recent results of the AETHER study revealed two deaths during the study period, one from IPF exacerbation and one from disease progression, over a 15-month period after IV stem cell therapy. Neither death was reported as being related to the study intervention [10]. However, due to the small samples, the diversity of disease states, and different methods employed, there is much information lacking regarding the short-term and long-term safety of the procedures.

Based on clinical presentation and CT scan findings, our patient met criteria for an acute exacerbation of IPF [2]. Temporal relationship suggested stem cell treatment as the likely trigger. In the recent AETHER study, treatment emergent adverse events were those occurring within 4 weeks of stem cell treatment [10]; our case met that definition. The clinical course made infection unlikely. Frequently, patients with acute exacerbation of IPF have diffuse alveolar damage superimposed on UIP. Given our patient's rapid improvement and possible link to stem cell inhalation or infusion, one could speculate that pathologically he had an organizing pneumonia, a hypersensitivity reaction or an eosinophilic pneumonia (though peripheral eosinophils were normal).

The above case raises concerns over the safety of stem cell therapy in IPF. These concerns have been elucidated in recent editorials on the topic [15-17]. Patients seeking stem cell therapy should only do so in the context of a reputable clinical research program. Clinicians must be diligent in explaining the unproven nature of stem cell therapy and the potential unknown side effects of this newly emerging option. Patients with life-threatening and orphan diseases are particularly susceptible to participating in unproven therapy as they grasp for any hope of relief from their disease. This makes them vulnerable to undergoing unproven therapies outside the context of a well-designed clinical trial.

\section{Conflict of Interest}

The authors declare that there is no conflict of interest.

\section{Author Contributions}

KLC, JR and PD wrote the initial draft of the article. All authors significantly contributed to and approved the final manuscript for publication.

\section{References}

1. Raghu G, Collard HR, Egan JJ, Martinez FJ, Behr J, Brown KK, Colby TV, et al. An official ATS/ERS/JRS/ ALAT statement: idiopathic pulmonary fibrosis: evidence-based guidelines for diagnosis and management. Am J Respir Crit Care Med. 2011;183(6):788-824.

2. Collard HR, Ryerson CJ, Corte TJ, Jenkins G, Kondoh Y, Lederer DJ, Lee JS, et al. Acute exacerbation of idiopathic pulmonary fibrosis. An international working group report. Am J Respir Crit Care Med. 2016;194(3):265-275.

3. Ryerson CJ, Cottin V, Brown KK, Collard HR. Acute exacerbation of idiopathic pulmonary fibrosis: shifting the paradigm. Eur Respir J. 2015;46(2):512-520.

4. Weiss DJ, Bertoncello I, Borok Z, Kim C, PanoskaltsisMortari A, Reynolds S, Rojas M, et al. Stem cells and cell therapies in lung biology and lung diseases. Proc Am Thorac Soc. 2011;8(3):223-272.

5. Alvarez D, Levine M, Rojas M. Regenerative medicine in the treatment of idiopathic pulmonary fibrosis: current position. Stem Cells Cloning. 2015;8:61-65.

6. Nejad-Moghaddam A, Panahi Y, Abdollahpour Alitappeh M, Borna H, Shokrgozar MA, Ghanei M. Therapeutic potential of mesenchymal stem cells for the treatment of airway remodeling in pulmonary diseases. Iran J Allergy Asthma Immunol. 2015;14(6):552-568.

7. Hecker L, Thannickal VJ. Nonresolving fibrotic disorders: idiopathic pulmonary fibrosis as a paradigm of impaired tissue regeneration. Am J Med Sci. 2011;341(6):431-434.

8. Stessuk T, Ruiz MA, Greco OT, Bilaqui A, Ribeiro-Paes MJ, Ribeiro-Paes JT. Phase I clinical trial of cell therapy in patients with advanced chronic obstructive pulmonary disease: follow-up of up to 3 years. Rev Bras Hematol 
Hemoter. 2013;35(5):352-357.

9. Glassberg M, Toonkel RL, Bejarano P, et al. Safety and tolerability of intravenous bone marrow derived human mesenchymal stem cells for patients with idiopathic pulmonary fibrosis. Am J Resp Crit Care Med. 2016;193(IC):A6433.

10. Glassberg MK, Minkiewicz J, Toonkel RL, Simonet ES, Rubio GA, DiFede D, Shafazand S, et al. Allogeneic human mesenchymal stem cells in patients with idiopathic pulmonary fibrosis via intravenous delivery (aether): a phase I safety clinical trial. Chest. 2017;151(5):971-981.

11. Tzouvelekis A, Paspaliaris V, Koliakos G, Ntolios P, Bouros E, Oikonomou A, Zissimopoulos A, et al. A prospective, non-randomized, no placebo-controlled, phase Ib clinical trial to study the safety of the adipose derived stromal cells-stromal vascular fraction in idiopathic pulmonary fibrosis. J Transl Med. 2013;11:171.

12. Serrano-Mollar A, Gay-Jordi G, Guillamat-Prats R, Closa D, Hernandez-Gonzalez F, Marin P, Burgos F, et al. Safety and tolerability of alveolar type II cell transplantation in idiopathic pulmonary fibrosis. Chest. 2016;150(3):533543.

13. Chambers DC, Enever D, Ilic N, Sparks L, Whitelaw K, Ayres J, Yerkovich ST, et al. A phase 1b study of placentaderived mesenchymal stromal cells in patients with idiopathic pulmonary fibrosis. Respirology. 2014;19(7):10131018.

14. Weiss DJ, Casaburi R, Flannery R, LeRoux-Williams M, Tashkin DP. A placebo-controlled, randomized trial of mesenchymal stem cells in COPD. Chest. 2013;143(6):1590-1598.

15. Marks PW, Witten CM, Califf RM. Clarifying stemcell therapy's benefits and risks. $N$ Engl J Med. 2017;376(11):1007-1009.

16. Charo RA. On the road (to a cure?) - stem-cell tourism and lessons for gene editing. N Engl J Med. 2016;374(10):901903.

17. Limper AH. Safety of IV human mesenchymal stem cells in patients with idiopathic pulmonary fibrosis. Chest. 2017;151(5):951-952. 